\title{
THE EFFECT OF THE NUMBER OF HIDDEN LAYERS IN THE BACKPROPAGATION IN CASE STUDY WEATHER CLASSIFICATION
}

\author{
Ang, Ester Verawati ${ }^{1}$, An. Nisa Santi Kiswanto ${ }^{2}$ \\ 1,2 Program Studi Teknik Informatika, Fakultas IImu Komputer, Universitas Katolik \\ Soegijapranata \\ 114k10017@student.unika.ac.id, 2ann.santi@unika.ac.id
}

\begin{abstract}
In this modern era, there are many algorithms that can be used to classify the weather, one of this algorithms is Backpropagation. Using Backpropagation, this research were using temperature, pressure, humidity, wind speed, rain and clouds as input parameters. And the output are clear, clouds and rain. Backpropagation consists of learning process and testing process. The learning process is to get optimal weight and testing process is to test the classification using the optimal weight from learning process. Data that was used in this research are 1600 data (80\%) for learning process and 400 data (20\%) for testing process. This research using Backpropagation with 1, 2 and 3 hidden layer to examine the accuracy result of weather classification. As a result, there is no significant changes of percentage accuracy on Backpropagation with 1, 2 and 3 hidden layers. But, the more number of hidden layer it used, the more epoch it requires.
\end{abstract}

Keywords: backpropagation, weather classification, hidden layer

\section{Pendahuluan}

Cuaca adalah salah satu faktor penting dalam kehidupan manusia. Cuaca mempengaruhi semua aktivitas manusia. Banyak aktivitas manusia membutuhkan prediksi cuaca. Sebagai contoh, orang membutuhkan prediksi cuaca untuk penjadwalan penerbangan, perencanaan kegiatan di luar ruangan, dll. Dengan kemajuan ilmu pengetahuan dan teknologi, kini cuaca bisa diprediksi dengan teknologi komputer. Dalam prediksi cuaca kota Semarang, cuaca dikelompokkan menjadi tiga kategori, yaitu clear, clouds dan rain. Cuaca dipengaruhi oleh banyak faktor, seperti suhu, tekanan udara, kelembaban, kecepatan angin, awan dan curah hujan.

Untuk mengklasifikasikan cuaca, dibutuhkan algoritma. Salah satu algoritma yang bisa digunakan untuk klasifikasi adalah Artificial Neural Network (JST). Jaringan Syaraf Tiruan (JST) adalah algoritma yang bekerja seperti jaringan saraf tubuh manusia. Backpropagation adalah salah satu metode dalam JST yang menggunakan dua proses penting, yaitu learning dan testing. Backpropagation menggunakan bobot dalam proses. Apabila Backpropagation dilatih dengan tepat, maka dapat digunakan untuk memecahkan masalah klasifikasi dan prediksi dengan baik. 
Backpropagation terstruktur dari input, hidden dan output layer. Salah satu faktor yang mempengaruhi hasil klasifikasi adalah jumlah hidden layer. Dalam penelitian ini dicari pengaruh jumlah hidden layer terhadap akurasi hasil klasifikasi cuaca. Penelitian ini menggunakan 1, 2, dan 3 hidden layer dengan jumlah node yang sama di setiap hidden layer. Data yang digunakan dalam penelitian ini adalah data klasifikasi cuaca kota Semarang.

\section{Landasan Teori}

\section{Jurnal Referensi}

Candra Dewi dan M.Muslikh. (2013) melakukan penelitian tentang prediksi cuaca pada kota Karangploso dan Banyuwangi. Input parameter yang digunakan adalah suhu, kelemababan udara, tekanan udara dan kecepatan angin. Peneitian tersebut membandingkan akurasi prediksi menggunakan metode ANFIS dan Backpropagation dengan 1 hidden layer. Didapatkan rata-rata akurasi di atas $80 \%$ pada Backpropagation dan di bawah 50\% pada ANFIS [1].

Risty Jayanti Yuniar, Didik Rahadi S., Onny Setyawati. (2013) melakukan penelitian tentang perbaikan metode prakiraan cuaca bandara Abdulrahman Saleh dengan algoritma ANN metode Backpropagation. Parameter input yang digunakan adalah temperatur, kelembaban udara dan tekanan udara. Parameter output yang digunakan adalah kecepatan angin dan curah hujan. Pada penelitian tersebut dilakukan percobaan arsitektur Backpropagation dan perbandingan learning rate 0.5, 0.7 dan 0.9. Pada studi kasus tersebut, didapatkan 3-5-2 sebagai arsitektur Backpropagation terbaik dengan learning rate 0.9 [2].

Cici Oktaviani, Afdal. (2013) melakukan penelitian prediksi curah hujan bulanan menggunakan JST metode Backpropagation. Adapun data yang digunakan adalah data Stasiun Meteorologi Tabing Padang tahun 2001-2012 sebagai data learning dan data tahun 2013-2014 sebagai data testing. Data tersebut dinormalisasi sebelum diproses menggunakan metode Backpropagation. Tujuan normalisasi data adalah mentransformasikan data dengan data terkecil 0.1 dan data terbesar 0.9. Rumus normalisasi sesuai dengan fungsi aktifasi yang digunakan yaitu sigmoid biner. Adapun rumus normalisasi yang digunakan:

$$
x^{\prime}=\frac{0.8(x-a)}{b-a}+0.1
$$

\section{Dimana:}

$\mathrm{x}=$ data yang akan dinormalisasi

$\mathrm{a}=$ nilai terkecil dari keseluruhan data

b = nilai terbesar dari keseluruhan data 
Dari penelitian tersebut, didapatkan Backpropagation dapat melakukan pengenalan pola mencapai $99.00 \%$ [3].

Dahriani Hakim Tanjung (2014-2015) melakukan penelitian tentang prediksi penyakit asma menggunakan Backpropagation. Input parameter yang digunakan sebanyak 18, terdiri dari berbagai gejala asma. Pola output yang digunakan adalah Asma Akut Persisten Ringan (0001), Asma Akut Persisten Sedang (0010), Asma Akut Persisten Berat (0100) dan Asma Akut Mengancam Jiwa (1000). Jumlah node optimal pada hidden layer diperoleh dengan percobaan, penelitian menggunakan 10 node pada hidden layer. Learning rate yang digunakan adalah 0.5, jumlah maksimum adalah 5000 dan batas error adalah 0.001. Data yang digunakan adalah 20 sampel data asma yang terdiri dari 6 data asma akut persisten ringan, 4 data asma akut persisten sedang, 6 data akut asma akut, 4 kematian akut - Mengingatkan data asma. Dari hasil penelitian didapatkan prediksi yang bisa mencapai akurasi 100\% [4].

I Putu Sutawinaya, I Nyoman Gede Arya Astawa, Ni Kadek Dessy Hariyanti. (2017) melakukan penelitian tentang perbandingan kesalahan prediksi dengan metode Backpropagation dan metode Adaline (Adaptive Linear Neuron). Adaline adalah single layer network yang berisi input dan output layer. Backpropagation adalah multilayer layer yang berisi input, hidden dan output layer. Data yang digunakan dalam penelitian ini adalah data curah hujan kota Denpasar tahun 2006-2016 dari BMKG. Parameter input yang digunakan adalah lima dengan satu prediksi output. Arsitektur jaringan pada metode Backpropagation adalah 5-5-1 dan pada metode Adaline adalah 5-1. Kesimpulan penelitian adalah metode Backpropagation yang diperoleh nilai RMSE lebih kecil dari pada metode Adaline. Nilai RMSE pada Backpropagation adalah 0.0435 dan pada Adaline adalah 0.0674 pada epoch 1000 [5].

Dwi Febby Haryati, Gunawan Abdillah, Asep Id Hadiana. (2016) melakukan penelitian tentang klasifikasi jenis batubara dengan menggunakan Backpropagation. Penelitian menggunakan tujuh input parameter, tiga nodes pada hidden layer dan lima output. Susunan pola output yang digunakan adalah Antrasit (10000), Sub-Bituminous (01000), Bituminous (00100), Lignit (00010) dan Gambut (00001). Data learning yang digunakan adalah 200 dan 500. Penelitian tersebut mencari learning rate optimal untuk mendapatkan akurasi terbaik. Kesimpulan dari penelitian tersebut, tingkat belajar yang optimal adalah 0.2, maksimal 1000, target MSE 0.001 dan 500 data learning [6].

\section{Backpropagation Formula}

Adapun rumus Backpropagation:

1. Hitung sinyal dari input dan bobot antara input dan hidden layer

$$
z_{i n j}=V_{0 j}+\sum_{i=1}^{n} X_{i} V_{i j}
$$


2. Hitung nilai pada hidden nodes dengan fungsi sigmoid biner

$$
Z_{j}=f\left(z_{i n j}\right)
$$

3. Hitung sinyal dari nilai hidden nodes dan bobot antara hidden dan output layer

$$
y_{i n k}=V_{0 j}+\sum_{i=1}^{n} Z_{j} W_{j k}
$$

4. Hitung nilai pada output nodes dengan fungsi sigmoid biner

$$
y_{k}=f\left(y_{i n k}\right)
$$

5. Hitung koreksi error dan perubahan bobot antara hidden dan output layer

$$
\begin{aligned}
& \delta_{k}=\left(t_{k}-Y_{k}\right) f^{\prime}\left(y_{i n k}\right) \\
& \Delta W_{j k}=\alpha \delta_{k} Z_{j}
\end{aligned}
$$

6. Hitung koreksi error dan perubahan bobot antara input dan hidden layer

$$
\begin{aligned}
& \delta_{i n j}=\sum_{k=1}^{m} \delta_{k} W_{j k} \\
& \delta_{j}=\delta_{i n j} f^{\prime}\left(z_{i n j}\right) \\
& \Delta V_{i j}=\alpha \delta_{j} X_{i}
\end{aligned}
$$

7. Update bobot dengan menjumlahkan nilai bobot lama dan perubahan bobot

$$
\begin{aligned}
& W_{j k}=W_{j k}+\Delta W_{j k} \\
& V_{i j}=V_{i j}+\Delta V_{i j}
\end{aligned}
$$

Dimana:

$Z_{\text {inj }}=$ sinyal hidden nodes yang terboboti

$\mathrm{V}_{0 \mathrm{j}}=$ bobot bias antara input dan hidden layer

$\mathrm{X}_{\mathrm{i}}=$ nilai input

$\mathrm{V}_{\mathrm{ij}}=$ bobot antara input dan hidden layer

$\mathrm{Z}_{\mathrm{j}}=$ nilai hidden

$\mathrm{y}_{\text {ink }}=$ sinyal output nodes yang terboboti

$\mathrm{W}_{\mathrm{jk}}=$ bobot antara hidden dan output layer

$\mathrm{Y}_{\mathrm{k}}=$ nilai output

$\delta_{\mathrm{k}}=$ nilai error yang dipropagasi balik ke hidden nodes

$\mathrm{t}_{\mathrm{k}}=$ target output 
$\alpha=$ learning rate

$\Delta \mathrm{W}_{\mathrm{jk}}=$ selisih bobot antara output dan hidden layer

$\delta_{\text {inj }}=$ jumlah delta input pada hidden layer dari output nodes

$\delta_{\mathrm{j}}=$ nilai error yang dipropagasi balik ke input nodes

$\Delta \mathrm{V}_{\mathrm{ij}}=$ selisih bobot antara input dan hidden layer

\section{Metodologi Penelitian}

1. Analisis Data

Langkah pertama adalah mengambil data prediksi cuaca kota Semarang dari situs openweathermap. Data yang digunakan sebagai input parameter sebanyak enam, yaitu suhu, awan, kelembaban, dan tekanan, kecepatan angin, curah hujan. Sedangkan parameter lainnya seperti tanggal, arah mata angin, salju tidak digunakan.

Dilakukan filterisasi data dengan menghilangkan data yang bernilai 0. Filterisasi data dilakukan untuk menghilangkan data yang tidak benar, sehingga tidak mempengaruhi hasil klasifikasi bila data diproses dalam proses learning dan testing menggunakan metode Backpropagation.

2. Desain

Sebelum memasuki proses learning dan testing, dilakukan normalisasi data. Data yang digunakan dalam proses learning adalah data cuaca kota Semarang pada tahun 2013-2016 yang telah dinormalisasi sebanyak 1.600 data. Proses learning menghasilkan bobot optimal yang akan digunakan dalam proses testing. Sedangkan proses testing digunakan untuk mengetahui klasifikasi cuaca kota Semarang dengan menggunakan bobot yang telah diperoleh dari proses learning. Data yang digunakan dalam proses testing adalah data kota Semarang tahun 2017 yang telah dinormalisasi sebanyak 400 data. Proses testing menghasilkan persentase akurasi Backropagation dengan lapisan tersembunyi 1, 2, dan 3.

3. Implementasi

Penelitian ini dibuat menggunkan bahasa pemrograman Java, aplikasi tampilan menggunakan javac.swing, data struktur array 2 dimensi. Implementasi penelitian ini terdiri dari proses kalsifikasi menggunakan metode Backpropagation dan aplikasi GUI.

4. Testing

Pada proses testing, aplikasi digunakan untuk menentukan klasifikasi cuaca Kota Semarang. Dari proses testing dapat disimpulkan pengaruh jumlah hidden layer. Kesimpulan berdasarkan hasil persentase akurasi dari Backpropagation dengan 1, 2 dan 3 hidden layer. Hasil persentase dihitung menggunakan rumus: 


$$
\text { accuracy }=\frac{\text { count of true value }}{\text { count of testing data }} \times 100
$$

\section{Hasil dan Pembahasan}

Backpropagation dengan 1, 2 dan 3 hidden layer dianalisis menggunakan jumlah epoch dan batas error. Output cuaca yang dihasilkan yaitu clear, clouds dan rain. Bobot random yang digunakan antara -1 sampai 1. Data yang digunakan adalah 1600 data pada proses learning dan 400 data pada proses testing. Pada analisa berdasar batas error, batas error yang digunakan adalah 0.01, 0.005 dan 0.001 dengan batas maksimum epoch 5000. Pada analisa berdasar jumlah epoch, maksimum epoch yang digunakan adalah 50, 40 dan 30 epoch. Hasil analisa sebagai berikut:

\section{Batas error 0.01}

Tabel 1: Backpropagation 1 Hidden Layer dengan Batas Error 0.01

\begin{tabular}{cccccc}
\hline & Result $\mathbf{1}$ & Result 2 & Result 3 & Result 4 & Result 5 \\
\hline Epoch & 16 & 15 & 15 & 17 & 14 \\
MSE & 0.01 & 0.01 & 0.01 & 0.01 & 0.01 \\
Akurasi & 0.99 & 0.99 & 0.99 & 0.99 & 0.98 \\
\hline
\end{tabular}

Tabel 2: Backpropagation 2 Hidden Layer dengan Batas Error 0.01

\begin{tabular}{cccccc}
\hline & Result 1 & Result 2 & Result 3 & Result 4 & Result 5 \\
\hline Epoch & 24 & 23 & 27 & 24 & 28 \\
MSE & 0.01 & 0.01 & 0.01 & 0.01 & 0.01 \\
Akurasi & 0.99 & 0.99 & 0.99 & 0.99 & 0.99 \\
\hline
\end{tabular}

Tabel 3: Backpropagation 3 Hidden Layer dengan Batas error 0.01

\begin{tabular}{cccccc}
\hline & Result $\mathbf{1}$ & Result 2 & Result 3 & Result 4 & Result 5 \\
\hline Epoch & 36 & 30 & 27 & 41 & 39 \\
MSE & 0.01 & 0.01 & 0.01 & 0.01 & 0.01 \\
Akurasi & 0.99 & 0.99 & 0.99 & 0.99 & 0.99 \\
\hline
\end{tabular}

Dari tabel uji coba di atas, menggunakan batas error 0.01, dapat disimpulakan bahwa epoch pada Backpropagation dengan 3 hidden layer lebih banyak dan MSE lebih kecil. Rata-rata akurasi terendah pada Backpropagation dengan 1 hidden layer. 


\section{Batas Error 0.005}

Tabel 4: Backpropagation 1 Hidden Layer dengan Batas Error 0.005

\begin{tabular}{cccccc}
\hline & Result 1 & Result 2 & Result 3 & Result 4 & Result 5 \\
\hline Epoch & 27 & 30 & 34 & 32 & 30 \\
MSE & 0 & 0 & 0 & 0 & 0 \\
Akurasi & 0.99 & 0.99 & 0.99 & 0.99 & 0.99 \\
\hline
\end{tabular}

Tabel 5: Backpropagation 2 Hidden Layer dengan Batas Error 0.005

\begin{tabular}{cccccc}
\hline & Result 1 & Result 2 & Result 3 & Result 4 & Result 5 \\
\hline Epoch & 40 & 35 & 39 & 39 & 52 \\
MSE & 0 & 0 & 0 & 0 & 0 \\
Akurasi & 0.99 & 0.99 & 0.99 & 0.99 & 0.99 \\
\hline
\end{tabular}

Tabel 6: Backpropagation 3 Hidden Layer dengan Batas Error 0.005

\begin{tabular}{cccccc}
\hline & Result 1 & Result 2 & Result 3 & Result 4 & Result 5 \\
\hline Epoch & 46 & 48 & 66 & 35 & 49 \\
MSE & 0 & 0 & 0 & 0 & 0 \\
Akurasi & 0.99 & 0.99 & 0.99 & 0.99 & 0.99 \\
\hline
\end{tabular}

Dari uji coba Backpropagation dengan 1, 2 dan 3 hidden layer menggunakan batas error 0.005, didapatkan Backpropagation dengan 3 hidden layer membutuhkan lebih banyak epoch dan MSE yang dihasilkan lebih kecil daripada Backpropagation dengan 1 dan 2 hidden layer

\section{Batas Error 0.001}

Tabel 7: Backpropagation 1 Hidden Layer dengan Batas Error 0.001

\begin{tabular}{cccccc}
\hline & Result 1 & Result 2 & Result 3 & Result 4 & Result 5 \\
\hline Epoch & 646 & 715 & 2201 & 409 & 3680 \\
MSE & 0.01 & 0 & 0 & 0 & 0 \\
Akurasi & 0.99 & 0.99 & 0.99 & 0.99 & 0.99 \\
\hline
\end{tabular}


Tabel 8: Backpropagation 2 Hidden Layer dengan Batas Error 0.001

\begin{tabular}{cccccc}
\hline & Result 1 & Result 2 & Result 3 & Result 4 & Result 5 \\
\hline Epoch & 267 & 1689 & 346 & 569 & 1001 \\
MSE & 0 & 0 & 0 & 0 & 0 \\
Akurasi & 0.99 & 0.99 & 0.99 & 0.99 & 0.99 \\
\hline
\end{tabular}

Tabel 9: Backpropagation 3 Hidden Layer dengan Batas Error 0.001

\begin{tabular}{cccccc}
\hline & Result $\mathbf{1}$ & Result 2 & Result 3 & Result 4 & Result 5 \\
\hline Epoch & 608 & 1767 & 260 & 534 & 435 \\
MSE & 0 & 0 & 0 & 0 & 0 \\
Akurasi & 0.99 & 0.99 & 0.99 & 0.99 & 0.99 \\
\hline
\end{tabular}

Dari uji coba Backpropagation menggunakan batas error 0.001, diperoleh kesimpulan Backpropagation dengan 3 hidden layer menghasilkan nilai MSE yang lebih kecil daripada Backpropagation dengan 1 dan 2 hidden layer. Akurasi yang dihasilkan sama yaitu $99.25 \%$.

\section{Epoch 50}

Tabel 10: Backpropagation 1 Hidden Layer dengan Epoch 50

\begin{tabular}{cccccc}
\hline & Result 1 & Result 2 & Result 3 & Result 4 & Result 5 \\
\hline MSE & 0 & 0 & 0 & 0 & 0 \\
Akurasi & 0.99 & 0.99 & 0.99 & 0.99 & 0.99 \\
\hline
\end{tabular}

Table 11: Backpropagation 2 HIdden Layer dengan Epoch 50

\begin{tabular}{cccccc}
\hline & Result 1 & Result 2 & Result 3 & Result 4 & Result 5 \\
\hline MSE & 0 & 0 & 0 & 0.01 & 0.01 \\
Akurasi & 0.99 & 0.99 & 0.99 & 0.99 & 0.99 \\
\hline
\end{tabular}

Table 12: Backpropagation 3 Hidden Layer dengan Epoch 50

\begin{tabular}{cccccc}
\hline & Result 1 & Result 2 & Result 3 & Result 4 & Result 5 \\
\hline MSE & 0.01 & 0.01 & 0 & 0.02 & 0.01 \\
Akurasi & 0.99 & 0.99 & 0.99 & 0.99 & 0.99 \\
\hline
\end{tabular}


Dari ketiga tabel di atas dengan batas maksimum epoch sebanyak 50, dapat disimpulkan bahwa semakin banyak hidden layer, maka rata-rata nilai MSE yang dihasilkan semakin tinggi.

\section{Epoch 40}

Table 13: Backpropagation 1 Hidden Layer dengan Batas Epoch

\begin{tabular}{cccccc}
\hline 40 & Result 1 & Result 2 & Result 3 & Result 4 & Result 5 \\
\hline MSE & 0 & 0 & 0 & 0 & 0 \\
Akurasi & 0.99 & 0.99 & 0.99 & 0.99 & 0.99 \\
\hline
\end{tabular}

Table 14: Backpropagation 2 Hidden Layer dengan Batas Epoch 40

\begin{tabular}{cccccc}
\hline & Result $\mathbf{1}$ & Result 2 & Result 3 & Result 4 & Result 5 \\
\hline MSE & 0 & 0.01 & 0.01 & 0.01 & 0.01 \\
Akurasi & 0.99 & 0.99 & 0.99 & 0.97 & 0.99 \\
\hline
\end{tabular}

Table 15: Backpropagation 3 Hidden Layer dengan Batas Epoch 40

\begin{tabular}{cccccc}
\hline & Result 1 & Result 2 & Result 3 & Result 4 & Result 5 \\
\hline MSE & 0.02 & 0.01 & 0.01 & 0.05 & 0.02 \\
Akurasi & 0.99 & 0.99 & 0.99 & 0.99 & 0.99 \\
\hline
\end{tabular}

Dari tabel uji coba terhadap Backpropagation dengan 1, 2 dan 3 hidden layer menggunakan batas maksimum epoch sebanyak 40 dapat disimpulkan bahwa semakin banyak hidden layer maka nilai rata-rata MSE lebih tinggi.

\section{Epoch 30}

Tabel 11: Backpropagation 1 HIdden Layer dengan Batas Epoch 30

\begin{tabular}{cccccc}
\hline & Result 1 & Result 2 & Result 3 & Result 4 & Result 5 \\
\hline MSE & 0.01 & 0.01 & 0.01 & 0 & 0.01 \\
Akurasi & 0.99 & 0.99 & 0.99 & 0.99 & 0.98 \\
\hline
\end{tabular}


Tabel 12: Backpropagation 3 Hidden Layer dengan Batas Epoch 30

\begin{tabular}{cccccc}
\hline & Result 1 & Result 2 & Result 3 & Result 4 & Result 5 \\
\hline MSE & 0.03 & 0.01 & 0.03 & 0.03 & 0.01 \\
Akurasi & 0.99 & 0.99 & 0.99 & 0.98 & 0.99 \\
\hline
\end{tabular}

Dari tabel uji coba terhadap Backpropagation dengan 1, 2 dan 3 hidden layer menggunakan batas maksimum epoch sebanyak 30 dapat disimpulkan bahwa semakin banyak hidden layer maka nilai rata-rata MSE lebih tinggi.

\section{Kesimpulan}

Pada studi kasus klasifikasi cuaca dengan metode Backpropagation dengan jumlah hidden layer yang berbeda, dilakukan analisis menggunakan batas error dan batas jumlah epoch. Dari hasil testing dapat disimpulkan bahwa tidak ada perubahan nilai akurasi yang signifikan pada Backpropagation dengan 1, 2 dan 3 hidden layer. Namun semakin banyak jumlah hidden layer maka epoch yang dibutuhkan semakin banyak dan nilai MSE yang dihasilkan semakin kecil.

\section{Daftar Pustaka}

[1] Dewi C., Muslikh M., "Perbandingan Akurasi Backpropagation Neural Network dan ANFIS Untuk Memprediksi Cuaca”, Journal of Scientific Modeling \& Computation, 2013.

[2] Yuniar R.J., S.Rahadi D., Setyawati O., "Perbaikan Metode Prakiraan Bandara Abdurahman Saleh dengan Algoritma Neural Network Backpropagation”, Jurnal EECCIS, 2013.

[3] Oktaviani C, Afdal, "Prediksi Curah Hujan Bulanan Menggunakan Jaringan Syaraf Tiruan Dengan Beberapa Fungsi Pelatihan Backpropagation”, Jurnal Fisika Unand, 2013.

[4] Tanjung D.H., "Jaringan Syaraf Tiruan dengan Backpropagation untuk Memprediksi Penyakit Asma”, Citec Journal, 2015.

[5] Sutawinaya I.P., Astawa I.P.G.A., Hariyanti N.K.D., "Perbandingan Metode Jaringan Saraf Tiruan Pada Peramalan Curah Hujan”, Jurnal Logic, 2017.

[6] Haryati D.F., Abdillah G., Hadiana A.I., "Klasifikasi Jenis Batubara Menggunakan Jaringan Syaraf Tiruan dengan Algoritma Backpropagation”, SENTIKA, 2016. 